\title{
KEMAMPUAN BERTANYA DAN KEAHLIAN MEMBACA: KAJIAN PADA MAHASISWA NON-BAHASA INGGRIS UNIVERSITAS ISLAM LAMONGAN
}

\author{
Lilik Uzlifatul Jannah ${ }^{1}$, Ike Susanti ${ }^{2}$ \\ ${ }^{12}$ Prodi Manajemen Universitas Islam Lamongan \\ E-mail: lilik_uj@yahoo.com
}

\begin{abstract}
The purpose of this study was to determine the ability of students to formulate questions in English. This research employed descriptive qualitative method using simple analysis techniques based on grammatical and semantic analysis. Questions made by students are based on reading at the literal level or basic level. The research subjects involved 80 students in the Non-English Study Program in the second semester Management Study Program Lamongan Islamic University. The results of the study were obtained as follows (1). Students were able to formulate questions in English as many times, even if they do not meet the grammatical and semantic rules. (2). Students' mistakes in formulating questions in English based on reading text including grammatical errors (60\%) either errors in semantics or meanings (40\%); and (3). Students still use translating techniques in formulating questions so that the strong influence of the use of the first language (Indonesian) and the rules of writing in the Indonesian language can be obviously seen. Finally, it can be concluded that the students' reading skill is at the lower cognitive level or at literal phase.
\end{abstract}

Keywords: speech ability; answer ability; reading skills; grammatical; semantics.

\begin{abstract}
ABSTRAK
Penelitian ini bertujuan untuk mengetahui kemampuan siswa dalam menformulasikan pertanyaan dalam Bahasa Inggris. Penelitian ini menggunakan metode deskriptif kualitatif dengan menggunakan teknik analisis sederhana berdasarkan pada analisis gramatikal dan semantik. Pertanyaan yang dibuat oleh siswa berdasarkan pada bacaan pada level literal atau level dasar. Adapun subyek penelitian melibatkan 80 mahasiswa pada Program studi NonBahasa Inggris di Prodi Manajemen semester 2 Universitas Islam Lamongan. Hasil penelitian diperoleh sebagai berikut (1) Siswa dapat membuat formulasi pertanyaan dalam Bahasa Inggris sebanyak, meskipun tidak memenuhi kaidah gramatikal dan semantik.; (2) Kesalahan siswa dalam memformulasikan pertanyaan dalam Bahasa Inggris berdasarkan bacaan meliputi kesalahan gramatikal (60\%) dan kesalahan dalam semantik tau pemaknaan artikata (40 \%); dan (3) Siswa masih menggunakan teknik menerjemahkan dalam memformulasikan pertaanyaan sehingga pengaruh kuat penggunaan bahasa pertama (Bahasa Indonesia) dan kaidah penulisan dalam berbahasa Indonesia nampak terlihat. Yang pada intinya dapat disimpulkan bahwa keahlian membaca siswa masih pada tahap literal yakni pada level kognitif bawah.
\end{abstract}

Kata kunci: kemampuan bertanya; kemampuan menjawab; keahlian membaca; grarmatikal; semantik.

\section{PENDAHULUAN}

Ketrampilan membaca merupakan salah satu ketrampilan berbahasa yang sangat penting di mana guru dan siswa harus menggunakannya dalam kehidupan akademik sehari-hari. Ketrampilan ini bervariasi mulai dari menguraikan simbol, huruf, dan kata-kata pada teks bacaan hingga menafsirkan sumber online berdasarkan analisis wacana, pragmatik, dan bahkan perspektif sosiokultural. Wallace (2003) menyatakan peran guru menjadi signifikan dalam memediasi antara siswa dan pembaca.

Cara mengutip: Jannah, U. L., \& Susanti, I. (2019). Kemampuan Bertanya dan Keahlian Membaca: Kajian pada Mahasiswa Non-Bahasa Inggris Universitas Islam Lamongan. Inteligensi: Jurnal Ilmu Pendidikan, 2(1), 1-8 
Dalam konteks Indonesia di mana bahasa Inggris dianggap sebagai bahasa asing (EFL), membaca dianggap pengajaran bahasa Inggris tidak termasuk pemahaman mengajar membaca karena siswa telah dapat membaca dengan tujuan untuk mengembangkan keterampilan siswa untuk memahami makna laof kedua teks tertulis dalam konteks Bahasa Inggris Pembelajaran Bahasa Indonesia diarahkan untuk meningkatkan kemampuan yang dimiliki mahasiswa untuk berkomunikasi dengan baik, benar, dan tepat secara tertulis maupun lisan (Kamhar \& Lestari, 2019: 1). Pembelajaran bahasa juga menuntut literasi tinggi di kelas membaca pada pembelajaran Bahasa Inggris sebagai Bahasa Asing, maka sudah selayaknya harus dipraktekkan melalui peningkatan motivasi dan secara alami terlihat dalam konteks yang bermakna. Ketika peserta didik tertarik pada topik teks bacaan dan diberi kesempatan untuk menegosiasikan makna secara mandiri, mereka akan termotivasi untuk membahas berbagai hal dengan teman sebaya mereka, dan pada saat yang sama memperoleh bahasa untuk berkomunikasi.

Sebagaimana telah diketahui selama bertahun-tahun bahwa kemampuan bertanya merupakan keterampilan hidup yang penting dan keterampilan belajar dan berpikir yang utama. Banyak guru meyakini bahwa memfasilitasi keterampilan bertanya siswa adalah tujuan utama maka kita harus memiliki beberapa bentuk alat penilaian yang sesuai yang memungkinkan kita untuk menentukan apakah pengalaman belajar dan praktik mengajar yang kita letakkan di tempat memiliki dampak positif pada siswa 'keterampilan. Tampaknya ada sejumlah pertanyaan yang perlu kita jawab beberapa sebagai Bahasa Asing (EFL). Menurut Richards \& Renandya (2002) tujuan pengajaran bahasa Inggris dalam sistem pendidikan Indonesia adalah untuk memberikan peserta didik keterampilan membaca yang canggih yang memungkinkan mereka membaca dan memahami teks-teks yang berhubungan dengan sains dalam bahasa Inggris sumber daya untuk dikembangkan jika kita serius memengaruhi keterampilan bertanya siswa kita.

Ada dua masalah utama dalam keterampilan bertanya, keduanya terhubung tetapi satu telah disembunyikan karena kebingungan dalam ungkapan: Yang pertama adalah jenis pertanyaan dan yang kedua adalah keterampilan bertanya. Berikut ini adalah ide-ide Keterampilan Tanya Jawab yang diajukan oleh Masduqi (2011). Mengenai keterampilan bertanya, jelas bahwa siapa pun yang telah mengetahui berbagai jenis pertanyaan cenderung memiliki lebih banyak pengetahuan dan pemahaman daripada mereka yang belum pernah mengetahui atau mempelajarinya. Tampaknya juga logis bahwa seseorang dengan pengetahuan dan pemahaman ini berada dalam posisi yang lebih baik untuk dapat mengajukan berbagai jenis pertanyaan. Atas dasar permodelan ini, dan pemodelan berbagai jenis pertanyaan tampaknya menjadi sesuatu yang layak dilakukan untuk siswa agar mereka menjadi penanya yang lebih baik. Diantaranya dengan melakukan latihan dan praktik-praktik dalam membuat pertanyaan berdasarkan konteks tertentu, diantaranya melalui bacaan.

Keterampilan bertanya melibatkan kompetensi seseorang. Dibutuhkan lebih dari sekadar pengetahuan untuk memahami berbagai jenis pertanyaan untuk 
menjadikan seseorang penanya yang baik (Etemadzadeh \& Sefi, 2012). Ketrampilan bertanya ini adalah keterampilan yang akan meningkatkan kemampuan siswa dalam memformulasikan pertanyaan yang efektif yang akan memberdayakan mereka sebagai pembelajar. Oleh karena itu, penelitian ini dilakukan dengan dua perspektif: siswa diharapkan mampu merumuskan antrian dalam pola yang benar atau secara tata bahasa benar. Yang kedua, para penanya perlu mengetahui set dasar kosakata yang relevan dengan konteks atau masalah. Dalam penelitian ini, teks pemahaman bacaan disediakan sebagai konteks.

Beberapa penelitian telah dilakukan dalam upaya meningkatkan kemampuan membaca siswa melalui beberapa teknik, metode, dan pendekatan pembelajaran bahasa ddiantaranya, melalui pendwkatan interaktif (Hendriana \& Ahmad, 2017); metode pembelajaran quantum dengan fokus pada metode mindmapping (Martka \& Hermayawati, 2016); dan strategi pembelajaran resiprokal (Ahmadi \& Poourhosein, 2012). Adapun beberapa teknik, metode, dan pendekatan tersebut secara empiris telah menyatakan bahwa penggunaan teknik, strategi, metode maupun pendekatan tersebut dapat meningkatkan keahlian membaca siswa.

Berdasarkan latar belakang di atas, masalah penelitian difokuskan pada bagaimana siswa mampu membuat pertanyaan sebagaimana siswa diyakini mampu menjawab pertanyaan secara cepat. Adapun ujuan penelitian ini adalah untuk mengetahui kemampuan siswa dalam menformulasikan pertanyaan dalam Bahasa Inggris. Adapun hal ini dilakukan untuk mengetahui lebih jauh pemahaman siswa dalam memahami bacaan.

\section{METODE PENELITIAN}

Penelitian ini adalah deskriptif kualitatif. Penelitian ini berfokus pada analisis dokumen atau konten. Tujuannya adalah untuk mengidentifikasi karakteristik material yang ditentukan (Ary et al, 2006). Analisis konten banyak digunakan dalam pendidikan. Mengidentifikasi dan menganalisis kesalahan siswa adalah salah satunya. Selain itu, penelitian ini akan secara kualitatif menggambarkan pekerjaan siswa dalam merumuskan pertanyaan dalam hal (1) kesalahan tata bahasa; dan (2). kosakata yang relevan dengan konteks atau masalah dalam teks pemahaman bacaan.

Pertimbangan utama peneliti mengambil siswa semester 2 adalah mengingat mereka telah mendapatkan Mata Kuliah Bahasa Inggris di Semester tersebut. Responden penelitian adalah siswa dari mahasiswa non-Bahasa Inggris yang mengambil kursus bahasa Inggris pada semester ke-2. Data penelitian ini diperoleh melalui instrumen penelitian. Instrumen penelitian dalam penelitian ini adalah dokumen (jawaban siswa). Peneliti dan anggota penelitian akan berperan sebagai instrument utama dalam proses menganalisis data.

Berikut ini adalah uraian prosedur analisis data pengumpulan data: (1). Dokumen sumber primer dikumpulkan dari karya siswa dalam bentuk serangkaian pertanyaan yang dihasilkan oleh siswa, (2) Memilih media dari mana pengamatan akan dilakukan, (3). Merumuskan kategori pengkodean lengkap dan saling eksklusif, (4). Memutuskan rencana pengambilan sampel yang akan digunakan untuk mendapatkan sampel dokumen yang representatif. (5). Melatih para pembuat 
kode, sehingga mereka dapat secara konsisten menerapkan skema pengkodean yang telah dikembangkan dan dengan demikian berkontribusi pada keandalan analisis konten, dan yang terakhir (6) Menganalisis data yang melibatkan frekuensi, persentase, dan akun deskriptif.

\section{HASIL DAN PEMBAHASAN}

Hasil penelitian didapat dari dokumen jawaban 80 siswa dalam memformulasikan pertanyaan terhadap jawaban peneliti. Klasifikasi hasil pertanyaan Fort Knox dapat dilihat pada tabel 1 berikut.

Tabel 1 Hasil Pertanyaan "Fort Knox"

\begin{tabular}{|c|c|}
\hline Jenis Pertanyaan & Kategori \\
\hline $\begin{array}{l}\text { Where is the place of site } \\
\text { of the army post?(a) }\end{array}$ & $\begin{array}{l}\text { Benar secara } \\
\text { gramatikal } \\
\text { dan semantik }\end{array}$ \\
\hline $\begin{array}{l}\text { What is the name of place } \\
\text { that is used to save most } \\
\text { of the gold deposit? (b) }\end{array}$ & $\begin{array}{l}\text { Benar secara } \\
\text { gramatikal } \\
\text { dan semantik }\end{array}$ \\
\hline $\begin{array}{l}\text { Where is the security } \\
\text { devices? (c) }\end{array}$ & $\begin{array}{l}\text { Benar secara } \\
\text { gramatikal } \\
\text { dan semantik } \\
\text { Benar secara }\end{array}$ \\
\hline $\begin{array}{l}\text { Where is the most up-to- } \\
\text { date security device? (d) }\end{array}$ & $\begin{array}{l}\text { gramatikal } \\
\text { dan semantik } \\
\text { Benar secara }\end{array}$ \\
\hline $\begin{array}{l}\text { Where is bullion } \\
\text { depository located? }(f)\end{array}$ & $\begin{array}{l}\text { gramatikal } \\
\text { dan semantik } \\
\text { Benar secara }\end{array}$ \\
\hline $\begin{array}{l}\text { What is the name of the } \\
\text { military fort in US? ( } g \text { ) }\end{array}$ & $\begin{array}{l}\text { gramatikal } \\
\text { dan semantik }\end{array}$ \\
\hline $\begin{array}{l}\text { What is the name of a } \\
\text { military base owned by }\end{array}$ & $\begin{array}{l}\text { Benar secara } \\
\text { gramatikal }\end{array}$ \\
\hline America? $(h)$ & $\begin{array}{l}\text { dan semantik } \\
\text { Salah secara }\end{array}$ \\
\hline What is the fort? (i) & semantik \\
\hline $\begin{array}{l}\text { Another name for army } \\
\text { post is? }(j)\end{array}$ & $\begin{array}{l}\text { Salah secara } \\
\text { semantik } \\
\text { Salah secara }\end{array}$ \\
\hline $\begin{array}{l}\text { Whom to Kentucky is a } \\
\text { US army post? (k) }\end{array}$ & $\begin{array}{l}\text { gramatikal } \\
\text { dan semantik } \\
\text { Salah secara }\end{array}$ \\
\hline $\begin{array}{l}\text { To whom Kentucky is a } \\
\text { US army post site?(l) }\end{array}$ & $\begin{array}{l}\text { gramatikal } \\
\text { dan semantik }\end{array}$ \\
\hline $\begin{array}{l}\text { Where the latest security } \\
\text { devicess available are } \\
?(m)\end{array}$ & $\begin{array}{l}\text { Kesalahan } \\
\text { gramatikal }\end{array}$ \\
\hline
\end{tabular}

Berdasarkan tabel 1 diketahui bahwa sebagian besar siswa dapat menformulasikan pertanyaan berkenaan dengan tempat dalam hal ini "Fort Knox". Siswa mampu memformulasikan pertanyaan dengan bervariasi dan sesuai dengan jawaban yang ditanyakan (poin a,b,c,d,e,f,g, dan h). Adapun kesalahan yng dilakukan oleh siswa dalam hal ini kesalahan dalam hal gramatikal dan semantik sebagaimana dicontohkan pada poin (I,j,k,l, dan $\mathrm{m})$. Klasifikasi hasil pertanyaan Fort Knox dapat dilihat pada tabel 1 berikut dan penjelasan dibawahnya.

Tabel 2 Hasil Pertanyaan "Granite, steel, and Concrete"

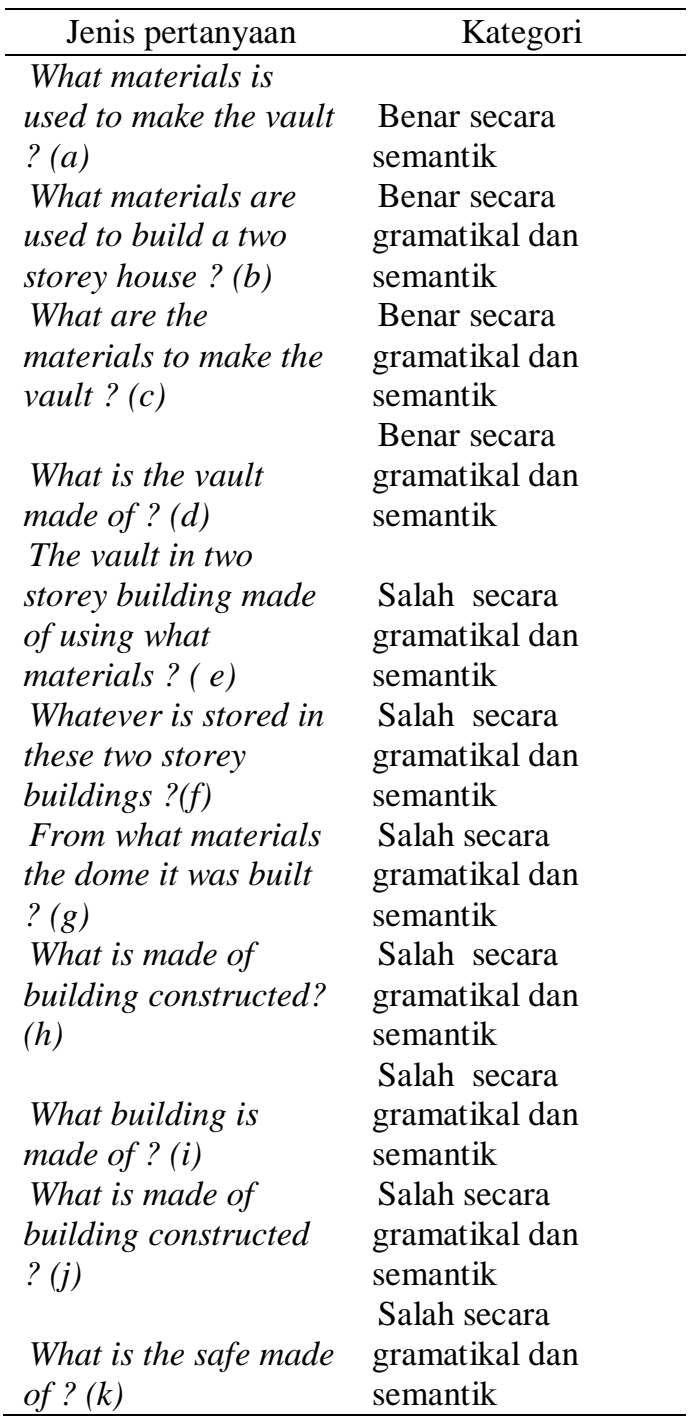


Berdasarkan tabel 2 diketahui beberapa siswa dapat menformulasikan pertanyaan dengan benar baik secara gramatikal maupun semantik (a,b,c,d dan e). Sedangkan, masih banyak siswa yang tidak bisa memformulasikan baik secara gramatikal maupun makna, begitu juga dengan kesalahan pada pilihan kata (poin f,g,h,I,j,dan k).

\section{Tabel 3 Hasil Pertanyaan "Army post"}

\begin{tabular}{|c|c|}
\hline Jenis pertanyaan & Kategori \\
\hline $\begin{array}{l}\text { Where is the gold bar } \\
\text { storage? (a) }\end{array}$ & $\begin{array}{l}\text { Benar secara } \\
\text { gramatikal } \\
\text { dan semantik }\end{array}$ \\
\hline $\begin{array}{l}\text { What is another name of fort } \\
\text { knox? (b) }\end{array}$ & $\begin{array}{l}\text { Benar secara } \\
\text { gramatikal } \\
\text { dan semantik }\end{array}$ \\
\hline $\begin{array}{l}\text { What are the uses of } \\
\text { building construction }\end{array}$ & $\begin{array}{l}\text { Benar secara } \\
\text { gramatikal }\end{array}$ \\
\hline materials? $(c)$ & $\begin{array}{l}\text { dan semantik } \\
\text { Benar secara } \\
\text { gramatikal }\end{array}$ \\
\hline What is fort knox? (d) & $\begin{array}{l}\text { dan semantik } \\
\text { Salah secara }\end{array}$ \\
\hline $\begin{array}{l}\text { What is the place for army } \\
\text { to guard? }(e)\end{array}$ & $\begin{array}{l}\text { gramatikal } \\
\text { dan semantik }\end{array}$ \\
\hline What is the function of Fort & $\begin{array}{l}\text { Salah secara } \\
\text { gramatikal }\end{array}$ \\
\hline Knox? $(f)$ & dan semantik \\
\hline $\begin{array}{l}\text { What is another name for } \\
\text { Fort Knox Bullion }\end{array}$ & $\begin{array}{l}\text { Salah secara } \\
\text { gramatikal }\end{array}$ \\
\hline Depository ? (g) & $\begin{array}{l}\text { dan semantik } \\
\text { Salah secara } \\
\text { gramatikal }\end{array}$ \\
\hline What is Fort Knox? (h) & $\begin{array}{l}\text { dan semantik } \\
\text { Salah secara }\end{array}$ \\
\hline $\begin{array}{l}\text { Who is provides further } \\
\text { protection? }(i)\end{array}$ & $\begin{array}{l}\text { gramatikal } \\
\text { dan semantik } \\
\text { Salah secara }\end{array}$ \\
\hline $\begin{array}{l}\text { What place fort Knox and } \\
\text { Kentucky? }(j)\end{array}$ & $\begin{array}{l}\text { gramatikal } \\
\text { dan semantik } \\
\text { Salah secara } \\
\text { gramatikal }\end{array}$ \\
\hline Kentucky is the $(k)$ & $\begin{array}{l}\text { dan semantik } \\
\text { Salah secara }\end{array}$ \\
\hline $\begin{array}{l}\text { Where we can search for } \\
\text { security devices? (l) }\end{array}$ & $\begin{array}{l}\text { gramatikal } \\
\text { dan semantik } \\
\text { Salah secara }\end{array}$ \\
\hline $\begin{array}{l}\text { Where nearby provides } \\
\text { further protection ? }(m)\end{array}$ & $\begin{array}{l}\text { gramatikal } \\
\text { dan semantik }\end{array}$ \\
\hline $\begin{array}{l}\text { Where does the place } \\
\text { provide further protection? } \\
\text { (n) }\end{array}$ & $\begin{array}{l}\text { Salah secara } \\
\text { gramatikal } \\
\text { dan semantik }\end{array}$ \\
\hline
\end{tabular}

Salah secara gramatikal Kentucky is the side of ? (o) dan semantik Salah secara gramatikal dan semantik
What is used for Knox Bullion Depository ? (p)
Berdasarkan tabel 3 dapat diketahui siswa melakukan banyak kesalahan dalam memformulasikan pertanyaan (poin e,f,g,h,i,j,k,l,m,n,o, p). Kesalahan tersebut meliputi pemilihan kosa kata yang tidak tepat, penggunaan tata bahasa, dan makna. Akan tetapi beberapa siswa dapat membuat pertanyaan (poin a,b,c,dan d) denga pola yang berbeda.

\section{Tabel 4 Hasil Pertanyaan tentang} "Kentucky"

\begin{tabular}{|c|c|}
\hline Jenis pertanyaan & Kelas Eksperimen \\
\hline $\begin{array}{l}\text { What states are } \\
\text { located in the Southern } \\
\text { part of the United States } \\
\text { ?(a) }\end{array}$ & $\begin{array}{l}\text { Benar secara } \\
\text { gramatikal dan } \\
\text { semantik }\end{array}$ \\
\hline $\begin{array}{l}\text { Mention one of the } \\
\text { army post in US! (b) }\end{array}$ & $\begin{array}{l}\text { Benar secara } \\
\text { gramatikal dan } \\
\text { semantik }\end{array}$ \\
\hline $\begin{array}{l}\text { Where city army posts } \\
\text { were built? }(c)\end{array}$ & $\begin{array}{l}\text { Benar secara } \\
\text { gramatikal dan } \\
\text { semantik } \\
\end{array}$ \\
\hline $\begin{array}{l}\text { Which city is the } \\
\text { government's historic } \\
\text { site? (d) }\end{array}$ & $\begin{array}{l}\text { Salah secara } \\
\text { gramatikal dan } \\
\text { semantik }\end{array}$ \\
\hline $\begin{array}{l}\text { What other name than } \\
\text { army post? }(e)\end{array}$ & $\begin{array}{l}\text { Salah secara } \\
\text { gramatikal dan } \\
\text { semantik } \\
\end{array}$ \\
\hline $\begin{array}{l}\text { Where is the location of } \\
\text { the army post? }(f)\end{array}$ & $\begin{array}{l}\text { Salah secara } \\
\text { gramatikal dan } \\
\text { semantik }\end{array}$ \\
\hline $\begin{array}{l}\text { What country is located } \\
\text { in the Southeast post of } \\
\text { US? }(\mathrm{g})\end{array}$ & $\begin{array}{l}\text { Salah secara } \\
\text { gramatikal dan } \\
\text { semantik }\end{array}$ \\
\hline $\begin{array}{l}\text { What is the name of the } \\
\text { city? (h) }\end{array}$ & $\begin{array}{l}\text { Salah secara } \\
\text { semantik }\end{array}$ \\
\hline $\begin{array}{l}\text { What is the name of the } \\
\text { US army post? (i) }\end{array}$ & $\begin{array}{l}\text { Salah secara } \\
\text { semantik }\end{array}$ \\
\hline $\begin{array}{l}\text { What is the name of the } \\
\text { area Fort Knox? }(j)\end{array}$ & $\begin{array}{l}\text { Salah secara } \\
\text { semantik }\end{array}$ \\
\hline $\begin{array}{l}\text { What is the name of the } \\
\text { site in US? }(k)\end{array}$ & $\begin{array}{l}\text { Salah secara } \\
\text { semantik }\end{array}$ \\
\hline $\begin{array}{l}\text { Tell one of the army } \\
\text { post in US? (l) }\end{array}$ & $\begin{array}{l}\text { Salah secara } \\
\text { semantik }\end{array}$ \\
\hline
\end{tabular}


What is the name of US army post site or better known for large storage $?(m)$

The army post was built in what city? ( $n$ )

The US site that is more famous for the Fort

Knox bullion depository is called? $(o)$

Berdasarkan tabel 4, beberapa siswa dapat menformulasikan pertanyaan dengan benar baik secara gramatikal maupun semantik (a,b,c, dan d). Sedangkan, masih banyak siswa yang tidak bisa memformulasikan baik secara gramatikal maupun makna, begitu juga dengan kesalahan pada pilihan kata (poin e,f,g,h,I,j,k,l,m,n, dan o).

Tabel 5 Hasil Pertanyaan tentang "1936"

\begin{tabular}{|c|c|}
\hline Jenis Pertanyaan & Kategori \\
\hline $\begin{array}{l}\text { What year was the the } \\
\text { site completed? (a) }\end{array}$ & $\begin{array}{l}\text { Benar secara } \\
\text { gramatikal dan } \\
\text { semantik }\end{array}$ \\
\hline $\begin{array}{l}\text { When is Fort Knox } \\
\text { completed to build? (b) }\end{array}$ & $\begin{array}{l}\text { Benar secara } \\
\text { gramatikal dan } \\
\text { semantik }\end{array}$ \\
\hline $\begin{array}{l}\text { In what year was the } \\
\text { government gold deposit } \\
\text { completed? }(c) \\
\text { In what year did Fort }\end{array}$ & $\begin{array}{l}\text { Salah secara } \\
\text { gramatikal dan } \\
\text { semantik }\end{array}$ \\
\hline $\begin{array}{l}\text { Knox bullion depository a } \\
\text { large safe containing a } \\
\text { large portion of US gold } \\
\text { deposits finished? (d) }\end{array}$ & $\begin{array}{l}\text { Salah secara } \\
\text { gramatikal dan } \\
\text { semantik }\end{array}$ \\
\hline $\begin{array}{l}\text { How many years the } \\
\text { American dome was built } \\
?(e)\end{array}$ & $\begin{array}{l}\text { Salah secara } \\
\text { gramatikal dan } \\
\text { semantik }\end{array}$ \\
\hline $\begin{array}{l}\text { What year was a large } \\
\text { dome in the US } \\
\text { completed? (f) }\end{array}$ & $\begin{array}{l}\text { Salah secara } \\
\text { gramatikal dan } \\
\text { semantik }\end{array}$ \\
\hline $\begin{array}{l}\text { What government gold } \\
\text { deposit has been } \\
\text { completed in what year? } \\
(\mathrm{g})\end{array}$ & $\begin{array}{l}\text { Salah secara } \\
\text { gramatikal dan } \\
\text { semantik }\end{array}$ \\
\hline $\begin{array}{l}\text { What year was } \\
\text { government deposit } \\
\text { completed? }(h)\end{array}$ & $\begin{array}{l}\text { Salah secara } \\
\text { gramatikal dan } \\
\text { semantik }\end{array}$ \\
\hline $\begin{array}{l}\text { In what year was the } \\
\text { government deposit } \\
\text { completed? (i) }\end{array}$ & $\begin{array}{l}\text { Salah secara } \\
\text { gramatikal dan } \\
\text { semantik }\end{array}$ \\
\hline
\end{tabular}

\begin{tabular}{|c|c|}
\hline $\begin{array}{l}\text { Gold government } \\
\text { deposits are completed in } \\
\text { what vear? }\end{array}$ & $\begin{array}{l}\text { Salah secara } \\
\text { gramatikal dan } \\
\text { semantik }\end{array}$ \\
\hline $\begin{array}{l}\text { The famous site was } \\
\text { completed in what year? } \\
(k)\end{array}$ & $\begin{array}{l}\text { Salah secara } \\
\text { gramatikal dan } \\
\text { semantik }\end{array}$ \\
\hline $\begin{array}{l}\text { Large dome that contains } \\
\text { most of US what year was } \\
\text { completed? }(l)\end{array}$ & $\begin{array}{l}\text { Salah secara } \\
\text { gramatikal dan } \\
\text { semantik }\end{array}$ \\
\hline The year how many Fort & $\begin{array}{l}\text { Salah secara } \\
\text { gramatikal dan }\end{array}$ \\
\hline Knox was build? (m) & semantik \\
\hline In the year when the & Salah secara \\
\hline $\begin{array}{l}\text { large dome completed the } \\
\text { building? (n) }\end{array}$ & $\begin{array}{l}\text { tikal dan } \\
\text { tik }\end{array}$ \\
\hline $\begin{array}{l}\text { US government } \\
\text { completes in what year? } \\
(o)\end{array}$ & $\begin{array}{l}\text { Salah secara } \\
\text { gramatikal dan } \\
\text { semantik }\end{array}$ \\
\hline ear of & $\begin{array}{l}\text { Salah secara } \\
\text { gramatikal dan }\end{array}$ \\
\hline
\end{tabular}

Berdasarkan Tabel 5 terlihat bahwa siswa banyak mengalami kesulitan dalam menggunakan tahun dalam memformulasikan kalimat tanya. Banyak yang masih terpengaruh pada penggunaan Bahasa Indonesia sebagai bahasa komunikasi sehari-hari. Akan tetapi dalam menanyakan tempat (Fort Knox, Kentucky, dan Army Post) siswa tidak mengalami kesulitan yang berarti sebagaimana dapat dilihat pada tabel 3 dan 4 . Lebih jauh lagi, terdapat banyak kesalahan yang dibuat dalam hal tata bahasa (grammar) dan kesalahan dalam memahami makna (semantik). Dua hal ini penting mengingat kesalahan tata bahasa dan semantik dapat mempengaruhi pesan dalam kalimat yang dibuat.

Satu hal yang merupakan faktor penting sebagaimana dijelaskan oleh Ahmad (2017) bahwa motivasi siswa dalam membaca mempunya dampak yang besaar dalam meningkatkan kemampuan membaca mereka, dengan dilakukannya praktik-praktik baik (best practices) dalam reading comprehension activities menambah pengetahuan siswa dalam 
memahami istilah-istilah dalam bacaan dan juga wawasan pengetahuan siswa akan meningkat dari tahap literal, inferensial, evaluatif dan pada tahap berpikir kritis dalam memahami bacaan. Pendapat ini dikuatkan lagi oleh Ahmadi \& Pourhosein (2012) dan Supriusma (2015) bahwa dengan kegiatan saling berbalas dalam bertanya dan menjawab (resiprokal) mengajarkan siswa bertanggungjawab akan apa yang mereka baca dan menerapkan strategi metakognitif di atas strategi membacav secara kognitif.

\section{SIMPULAN}

Berdasarkan hasil penelitian ini dapat disimpulkan bahwa siswa dapat membuat formulasi pertanyaan dalam Bahasa Inggris sebanyak, meskipun tidak memenuhi kaidah gramatikal dan semantik Selanjutnya, kesalahan siswa dalam memformulasikan pertanyaan dalam Bahasa Inggris berdasarkan bacaan meliputi kesalahan gramatikal $(60 \%)$ dan kesalahan dalam semantik tau pemaknaan artikata (40\%); dan terakhir yang harus segers diperbaiki siswa adalah siswa masih menggunakan teknik menerjemahkan dalam memformulasikan pertaanyaan sehingga pengaruh kuat penggunaan bahasa pertama (bahasa Indonesia) dan kaidah penulisan dalam berbahasa Indonesia nampak terlihat.

\section{DAFTAR PUSTAKA}

Ahmad, M.R.,\& Pourhosein, G.A (2012). Reciprocal Teaching Strategies and their Impacts on English Reading Comprehension. Theory and Practices in Language Studies Vol. 2 (10). pp. 2053-2060. DOI: 10.4304/tpls.2.10.

Ahmadi, M.R. (2017). The Impact of Motivation on Reading
Comprehension.

IJREE.

url://http://ijreeonline.com/article-

1.35en.html

Ary, D., Jacobs, L. C., Razavieh, A \& Sorensen, C (2006). Introduction to Research in Education. Canada: Thomson Wadsworth.

Darn, S (2000). Content and Language Integrated Learning. Retrieved on December, 5, 2018, from http://www.teachingenglish.org.uk/ try/lesson-plans/.

Etemadzadeh, A., Seifi, S., \& Far, H.R. (2012). The Role of Questioning Technique in Developing Thinking Skills: The Ongoing Effect on Writing Skills. Procedia- Social and Behavioral Sciences 70 (2013), pp. 1024-1031.

Henrdiana, A., \& Ahmad, D (2017) Improving Students' Reading Skill through Interactive Approach at the First Grade Students of SMAN 1 Mare Bone. English, Teaching, Learning, and Research Journal (ETERNAL) Journal. Vol. 3 (1) June 2017, pp. 44-56

Kamhar, M.Y., \& Lestari, E. (2019). Pemanfaat Sosial Media Youtube Sebagai Media Pembelajaran Bahasa Indonesia DI Perguruan Tinggi. Jurnal Inteligensi: Ilmu Pendidikan, UNITRI Press. 1(2), 17.

http://dx.doi.org/10.33366/ilg.v1i2. 1356

Kumaradivelu, B. (2006). TESOL Methods: Changing Tracks, Challenging Trends. TESOL Quarterly, 40 (pp 59-81)

Martika, W. \& Hermayawati (2016). Improving Students' Reading Skill by Using Quantum Learning. Journal of English Language and Education (JELE). Vol. 2 (2) June.

Masduqi, H. (2011). ESL Reading in Indonesia: Understanding Cultural Problem. In Tomasowa, F.H., Muttaqin, S. \& Fajar, Y. (eds) 
Systemic Functional Linguistics: "Applied" and Multiculturalism. Malang: Aditya Media Publishing. Richards, J. C., \& Renandya, W.A. (2002) Methodology in Language Teaching.: An Anthology of Current Practice. Cambridge: Cambridge University Press.

Supriusman. (2015). Questions and Questioning Skills. Journal of
English Literary Education: The Teaching and Learning of English as a Foreign Language. Vol, 2 (2). 58-68

https://ejournal.unsri.ac.id/index.ph $\mathrm{p} /$ jenglish.

Wallace, C. (2003). Critical Thinking in Language Education. New York: Palgrave: Macmillan Publishing. 